fundación

Manuel Giménez Abad

deEstudiosParlamentariosydelEstado Autonómico

\title{
LAS LIMITACIONES COMO DERECHO DEL DERECHO CONSTITUCIONAL DE EXCEPCIÓN
}

\author{
Carlos Garrido López \\ Profesor Titular de Derecho Constitucional, \\ Universidad de Zaragoza
}

Cómo citar este artículo / Citation: Garrido López, C. (2021). Las limitaciones como derecho del Derecho constitucional de excepción. Garrido López, C. (coord.) Excepcionalidad y Derecho: el estado de alarma en España, Colección Obras colectivas, Fundación Manuel Giménez Abad, Zaragoza.

DOI: https://doi.org/10.47919/FMGA.OC21.9999

SUMARIO: I. LA IRREDUCTIBLE TENSIÓN ENTRE EXCEPCIONALIDAD Y DERECHO. LAS DEBILIDADES DEL DERECHO CONSTITUCIONAL DE EXCEPCIÓN.- II. LAS OPCIONES DE NUESTRO DERECHO CONSTITUCIONAL DE EXCEPCIÓN COMO DERECHO LATENTE.- III. EL DERECHO DE EXCEPCIÓN EN ACCIÓN: SUS RIGIDICES, INSUFICIENCIAS Y LAGUNAS BAJO LOS ESTADOS DE ALARMA DECLARADOS EN ESPAÑA EN 2010 Y 2020.

I. LA IRREDUCTIBLE TENSIÓN ENTRE EXCEPCIONALIDAD Y DERECHO. LAS DEBILIDADES DEL DERECHO CONSTITUCIONAL DE EXCEPCIÓN

Toda Constitución está redactada con vistas a su vigencia y aplicación en situaciones de normalidad. Pero la normalidad constitucional no puede excluir su reverso: la estabilidad puede dar paso a la crisis y la sociedad puede verse amenazada por acontecimientos extraordinarios. En estas circunstancias, el Estado, como aparato político de la comunidad, tiene la obligación de actuar recabando para sí el poder para adoptar medidas excepcionales. En los países 
anglosajones, dicho poder se ha ejercido tradicionalmente ad hoc y sin límites normativos prefijados, recurriendo a la ley marcial, a las exoneraciones parlamentarias ex post facto y a las leyes de plenos poderes según resultaran de imprevisibles o extraordinarias las emergencias. En el continente europeo, varios países también ignoraron normativamente la excepción, lo que condujo asimismo a la aprobación a posteriori de leyes de indemnidad o al otorgamiento de plenos poderes. Y con idéntico objeto se acogió la doctrina del estado de necesidad (Staatsnotrecht) desarrollada entre otros por Ihering, Jellinek y Köhler y gráficamente expresada en el título de la obra de este último: Not kennt kein gebot ${ }^{1}$. Al amparo de dicha doctrina, el Estado carecía de ataduras legales ante la excepción porque, enfrentado al dilema de sacrificar el derecho o la sociedad, su autolimitación normativa (Selbstverpflichtung) debía ceder en interés de aquella ${ }^{2}$.

A fin de racionalizar el ejercicio del poder de excepción, otros países europeos fueron incorporando a sus ordenamientos jurídicos un marco habilitador de las decisiones excepcionales, lo que dio lugar al derecho constitucional de excepción. Esta opción también implicaba el sacrificio temporal del orden jurídico, pero, frente al silencio o la exclusión normativa de la excepción, tenía la ventaja de activar una "constitución alternativa de emergencia" que evitara la imposición de la fuerza normativa de lo fáctico ${ }^{3}$. La adopción de medidas excepcionales pasó a tener una cobertura normativa previa que hacía innecesaria la delegación de poderes extraordinarios o la posterior convalidación de las actuaciones ilegales. Surgió así el modelo de estado excepcional, que representa el máximo esfuerzo por extender el imperio de la ley a las situaciones excepcionales al prever una legalidad latente que poder activar para hacerles frente. Su objetivo es enfrentar la situación crítica y superarla cuanto antes, pero también protegerse frente a sí mismo. El modelo de estado excepcional habilita a la par que limita. Potencia la eficacia de los

\footnotetext{
${ }^{1}$ KÖHLER, J., Not kennt kein gebot. Die theorie des notrechts und die ereignisse unserer zeit, Verlagsbuchhendlung Dr. W. Rothschild, 1915.

${ }^{2}$ Sobre el estado de necesidad, los bills of indemnity o exoneraciones parlamentarias y las leyes de plenos poderes, véase en la doctrina española ÁLVAREZ GARCíA, V., El concepto de necesidad en Derecho Público, Civitas, Madrid, 1996, pp. 91-130. Más reciente, sobre estas técnicas, GREENE, A., States of Emergency and the Rule of Law. Constitutions in an Age of Crisis, Hart Publishing, Oxford, 2018, pp. 163-195.

${ }^{3}$ CRUZ VILLALÓN, P., Estados excepcionales y suspensión de garantías, Tecnos, Madrid, 1984, p. 19.
} 
poderes públicos sin llegar al extremo de una concentración de poder o de una supresión de derechos que carezca de límites, altere el principio de responsabilidad o cuestione el retorno a la normalidad constitucional. Por ello en este modelo el constituyente o, por delegación suya, el legislador pretenden tipificar los supuestos excepcionales y las medidas extraordinarias a adoptar. $Y$ por ello determinan el órgano competente para activar los poderes de excepción y establecen frenos y controles al ejercicio de dichos poderes. Cada una de estas operaciones jurídicas suscita, sin embargo, una problemática no menor que compromete la normatividad del resultado.

La realidad excepcional es inaprensible e imprevisible, lo que hace que la tipificación normativa de las emergencias "tenga más el carácter de apertura de un procedimiento especial de manifestación de la voluntad del Estado, a partir de la interpretación que realiza el titular de los poderes extraordinarios sobre su propia competencia, que el de la descripción jurídica de situaciones incontrovertibles"4. La previsión de las situaciones excepcionales no puede realizarse, por ello, sino genéricamente mediante la utilización de conceptos jurídicos indeterminados referidos a los elementos fáctico y teleológico de las crisis. Se trata, como Solozábal Echavarría ha recordado, más de configurar "un marco que una base propiamente dicha, con un sentido habilitador más que referencial”, porque la norma no puede prever todas las situaciones ${ }^{5}$. De ahí el frecuente empleo de cláusulas generales, de enumeraciones abiertas y de fórmulas de habilitación universal, así como la inviabilidad, a la postre, de las tipificaciones cerradas pretendidamente taxativas que la excepción suele desbordar.

Pese al esfuerzo de racionalización jurídica, también en este modelo el titular del poder de excepción decide sobre la concurrencia de la crisis y determina, con su decisión, el alcance de las medidas extraordinarias a adoptar. El derecho puede proporcionarle criterios de interpretación, pero es el titular de ese poder el administrador último de la normalidad y la anormalidad constitucionales. $\mathrm{Y}$, en el preciso momento de la decisión sobre el estado

\footnotetext{
${ }^{4}$ PORRES AZKONA, J., "La decisión sobre poderes excepcionales", Revista Vasca de Administración Pública, núm. 6, 1983, pp. 46-47.

${ }^{5}$ SOLOZÁBAL ECHAVARRÍA, J. J., "Algunas consideraciones constitucionales sobre el estado de alarma", en BIGLINO CAMPOS, P. y DURÁN ALBA, J. F. (dirs.), Los efectos horizontales de la COVID-19 en el sistema constitucional: estudios sobre la primera oleada, Fundación Manuel Giménez Abad, Zaragoza, 2021, p. 22.
} 
excepcional, es su voluntas y no la norma la que decide, como advirtió Carl Schmitt al relacionar dicha voluntas con los atributos de la soberanía ${ }^{6}$. La cuestión del órgano competente para declarar la entrada en vigor de los poderes excepcionales no es, en suma, un simple problema técnico, sino una cuestión política de primer orden. La declaración de un estado excepcional es, en palabras de Camus, "la source de toutes les décisions ultérieures, et surtout c'est elle qui apporte le plus grand bouleversement à l'ordre constitutionnel démocratique à partir de l'appréciation d'une situation formée essentiellement d'éléments d'ordre politique" ${ }^{\prime 7}$. Por razones de eficacia, cabría atribuir dicha decisión a los gobiernos, quienes disponen de los poderes necesarios para ejecutarla. Atendiendo, sin embargo, a la representatividad popular que los parlamentos poseen, deberían ser estos quienes asumieran esa responsabilidad, porque debido a su alcance y efectos "[...] the power to suspend the laws should always be lodged in the hands of those to whom the people have entrusded their making", subrayó Rossiter ${ }^{8}$. Un dilema que el derecho de excepción ha de enfrentar.

En el modelo de estado excepcional, el legislador también debe determinar las posibles derogaciones del derecho ordinario y enumerar las respuestas jurídicas o medidas standard aplicables. El problema estriba en que, dado el carácter imprevisible de las situaciones de emergencia, la capacidad del legislador para regular apriorísticamente dichas medidas extraordinarias resulta muy limitada. En la práctica, debe recurrirse al principio de necesidad, que, como evidencia la agitada historia francesa del derecho de excepción o la peculiar carta blanca otorgada a dicho principio en Suiza, lleva a los poderes públicos a adoptar derogaciones o apoderamientos sin habilitación suficiente. En el caso de Francia, la limitada eficacia de su estado de sitio llevó al Conseil d'État a elaborar la doctrina de las circunstancias excepcionales, que exoneraba ex post facto las medidas ilegales adoptadas atendiendo a su

\footnotetext{
${ }^{6}$ "Quien domine el estado de excepción domina con ello al Estado, porque decide cuándo debe existir ese estado y qué es lo que la situación de las cosas exige". SCHMITT, C., La dictadura, Alianza, Madrid, 1985, p. 49.

${ }^{7}$ CAMUS, G., L'état de nécessité en démocratie, Librairie générale de droit et de jurisprudence, Paris, 1965, p. 346.

${ }^{8}$ ROSSITER, C., Constitutional Dictatorship. Crisis Government in the Modern Democracies, Harcourt, Brace \& Workd, Inc, New York, 1963, p. 84.
} 
necesidad ${ }^{9}$. En Suiza, también la necesidad justificó las actuaciones contra legem en circunstancias excepcionales ${ }^{10}$ y la idea de prever las medidas extraordinarias ha sido rechazada recientemente por el Consejo Federal, al considerar que su regulación sería "laborieux, inutile et pas sans risque" y que su pretendido detalle dificultaría actuar conforme exigieran las circunstancias ${ }^{11}$. Previstas o no taxativamente, la adopción y aplicación de las medidas excepcionales en una concreta situación crítica deben regirse en todo caso por el principio de proporcionalidad, único que permite "conciliar intereses contrapuestos, a veces incluso de rango constitucional, buscando un punto de equilibrio específico para cada conflicto, [...] que encuentra su expresión en cada concreta medida" ${ }^{12}$. Conforme a dicho principio, sólo estarán justificadas aquellas medidas y derogaciones del derecho ordinario que, siendo lo menos lesivas posibles, resulten necesarias y cuyos efectos negativos no superen los positivos derivados de la consecución de la normalidad. Pero debemos ser realistas: el alcance del principio dependerá, a la postre, de la decisión del titular del poder de excepción y del criterio del intérprete que juzgue a posteriori su adecuación constitucional.

En el modelo de estado excepcional, el control jurisdiccional debe estar garantizado. Y no sólo de los actos o medidas adoptados por el beneficiario de la concentración de poderes, cuya revisión ha de corresponder a los juzgados y tribunales de todos los órdenes, especialmente al orden contenciosoadministrativo, sino también de las decisiones que declaran la emergencia y activan el estado excepcional correspondiente. Debido a su extraordinario alcance y a su carácter esencialmente político, las decisiones de declaración y de prórroga de los estados excepcionales no tienen, sin embargo, un fácil

\footnotetext{
${ }^{9}$ Por todos, NIZARD, L., La jurisprudence administrative des circonstances exceptionnelles et la légalité, Librairie générale de droit et de jurisprudence, Paris, 1962, pp. 82 y ss.

${ }^{10}$ Véase HOERNI, R., De l'état de nécessité en droit public federal suisse, Société générale d'imprimerie, Genève, 1917, para quien "[...] l'exercice d'un droit de nécessité n'a pas besoin d'être mentionné à l'avance [...] pour être possible et légitime. Il est justifié par les circonstances elles-mêmes, qui donnent naissance à un droit nouveau dont la rigueur prime celle du droit existant' (p. 185).

11 "Une nouvelle réglementation du droit de nécessité ne s'impose pas", Communiqués, Federal Department of Justice and Police, 16 June 2006. Disponible en: http://www.ejpd.admin.ch/ejpd/fr/home/dokumentation/mi/2006/2006-06-160.html.

${ }^{12}$ ÁLVAREZ GARCíA, V., El concepto de necesidad en Derecho Público, cit., p. 462.
} 
control jurisdiccional $^{13}$. La mayoría de las constituciones europeas guardan silencio sobre la cuestión. En algunos países, como Hungría o Suecia, dichas decisiones han sido expresamente excluidas de revisión por parte de los tribunales. En Irlanda, Grecia o Chipre el control es posible, pero sólo por razones de forma, limitado a verificar si las reglas procedimentales y competenciales son respetadas. El control de constitucionalidad sobre su contenido es, en cambio, posible en Francia, Alemania y Portugal; y significativamente en Eslovaquia, donde el control de la proclamación se atribuye explícitamente al tribunal constitucional ${ }^{14}$. El problema es que, incluso cuando el control jurisdiccional está garantizado, la justicia no reduce la "plusvalía política adicional" de la decisión del titular del poder de excepción, esa "prima supralegal a la posesión legal del poder legal" sobre la que Schmitt teorizó $^{15}$. La justificación de la declaración de los estados excepcionales y la adecuación de las medidas adoptadas se sustenta, además, sobre conceptos jurídicos indeterminados cuya determinación en función de las circunstancias concretas difícilmente cabe contrastar con un parámetro constitucional cierto. El control jurisdiccional de los presupuestos de la emergencia y de las medidas es, por los factores citados, muy relativo. Y sólo un exceso de optimismo en el carácter objetivado de la interpretación llevada a cabo por el órgano controlante puede llevar a no reconocer los criterios de oportunidad que dicho control encierra y que conducen a su autolimitación. Fiat iustitia pereat mundus o salus populi suprema lex esto, son los términos de la difícil disyuntiva en la que el juez constitucional suele guiarse con una extraordinaria prudencia bajo el peso de su responsabilidad en el mantenimiento del orden jurídico-estatal ${ }^{16}$.

\footnotetext{
${ }^{13}$ GREENE, A., States of Emergency and the Rule of Law. Constitutions in an Age of Crisis, cit., pp. 113-119.

${ }^{14}$ Véanse ÖZBUDUN, M. E., "Pouvoirs d'exception et contrôle jurisditionnel", en VV.AA., Droits de l'homme et fonctionnement des institution démocratiques dans des situations d'urgence, Conseil de l'Europe, Strasbourg, 1997, pp. 18-19, y KHALEE, A., "Security democracy?. A comparative analysis of Emergency Powers in Europe", Geneva Centre for the Democratic Control of the Armed Forces. Policy Papers, núm. 30, 2009, p.16.

${ }^{15}$ SCHMITT, C., Legalidad y legitimidad, Madrid, Aguilar, 1971, p. 49.

16 "[...] en une époque tourmentée, le juge ne peut aller à contre-courant. II ne peut prétendre défendre, à lui seul, le droit alors que le Parlement, soit accorde les pouvoirs exceptionnels, soit se montre très conciliant envers les inicitiaves de l'Exécutif. [...] La violation de la Constitution non sanctionnée, politiquement, ne peut faire facilement l'objet d'une condamnation juridictionnelle. La crise n'est pas loin de placer le juge hors jeu'. Cfr. LEROY, P., L'organisation constitutionnelle et les crises, Librairie générale de droit et de jurisprudence, Paris, 1963, p. 129.
} 
Debido a todas estas limitaciones, alguna doctrina ha llegado a sostener que el derecho excepcional es la forma jurídica de lo que no puede adoptar forma jurídica, lo que representa una paradoja irresoluble. "Si lo propio del estado de excepción -ha subrayado Agamben- es la suspensión (total o parcial) del ordenamiento jurídico, ¿cómo puede tal suspensión estar comprendida en el orden legal?" ${ }^{17}$. Para la mayoría de la doctrina, sin embargo, el derecho de excepción no alberga paradoja alguna, porque no es un derecho al margen del derecho, ni convierte la excepción en regla. En primer lugar, porque en los estados de excepción no se produce una suspensión completa del derecho y, en segundo, porque dicha suspensión o excepción está definida y configurada por el propio derecho, que sigue cumpliendo su función al habilitar la aplicación de un marco jurídico que sustituye a otro limitando el sacrificio en que la terapia puede consistir $^{18}$. La eficacia normativa de este marco depende, no obstante, de sus singulares condiciones de realización, que son siempre excepcionales y de las que deriva la extraordinaria tensión que debe soportar. El derecho constitucional de excepción arrastra, por ello, unas limitaciones que en absoluto cabe soslayar, porque forman parte de su naturaleza y condicionan su vigencia.

\section{LAS OPCIONES DE NUESTRO DERECHO CONSTITUCIONAL DE EXCEPCIÓN COMO DERECHO LATENTE}

En el modelo de estado excepcional, el constituyente o, en su defecto, el legislador identifican con pretensión normativa los tipos de emergencias, determinan la competencia para apreciar su concurrencia, enumeran el elenco de medidas a adoptar, subrayan su carácter limitado temporal, espacial y materialmente y definen el núcleo constitucional intangible y resistente a la excepción. Pero nada de esto, como se acaba de subrayar, es tarea fácil porque la excepción es refractaria al derecho y, cuando concurre, evidencia

\footnotetext{
${ }^{17}$ En el derecho excepcional, continúa el autor, "la suspensión de la norma no significa su abolición, y la zona de anomia que ella instaura no está (o al menos pretende no estar) totalmente escindida del orden jurídico. [...] pero se trata de una articulación paradójica, porque aquello que debe estar inscrito en el interior del derecho es algo esencialmente exterior a él, ya que se corresponde, nada menos, con la suspensión del propio orden jurídico". Cfr. AGAMBEN, G., Estado de excepción, Adriana Hidalgo editora, Buenos Aires, 2005, pp. 59 y 72-73.

${ }^{18}$ TROPER, M., "El estado de excepción no tiene nada de excepcional", Revista de Derecho Constitucional Europeo, núm. 27, 2017, pp. 7-10. Disponible en: https://www.ugr.es/ redce/REDCE27/articulos/08_TROPER.htm.
} 
que poco encaja en el marco normativo prefijado. De ahí las insuficiencias, omisiones y lagunas que a menudo se denuncian como fracasos del derecho constitucional de excepción por quienes, imbuidos de suficiencia y positivismo jurídicos, sostienen que es posible preverlo todo.

Con bastante humildad y realismo, nuestro constituyente de 1978 abrazó el modelo de estado excepcional reconociendo tres estados distintos: alarma, excepción y sitio, pero no pretendió preverlo todo, ni agotar el derecho de excepción. Al contrario que el Verfassungsnotstand de la Ley Fundamental de Bonn, los estados de anomalía regulados en los artículos 55.1 y 116 de la CE no son institutos inmediatamente aplicables por los poderes públicos a partir de su enunciado constitucional. El primero de dichos preceptos concreta, con carácter de numerus clausus, los derechos y libertades cuyo ejercicio puede ser suspendido bajo los estados de excepción y de sitio. El segundo regula formas y procedimientos de declaración de los tres estados, señala límites temporales y proclama la indisolubilidad de las Cámaras bajo su vigencia, así como, entre otras garantías, la intangibilidad del principio de responsabilidad de los poderes públicos, pero no identifica las situaciones excepcionales a las que cada estado debe hacer frente ni precisa los apoderamientos extraordinarios a que pueden dar lugar ${ }^{19}$. La Constitución omite estas cuestiones, encomendando al legislador su concreción. "Una ley orgánica regulará los estados de alarma, de excepción y de sitio, y las competencias y limitaciones correspondientes", proclama el artículo 116.1 de la CE, convirtiendo esa regulación en pieza necesaria y fundamental del sistema de fuentes del derecho español de excepción, por cuanto dicha ley debía ser la que definiera la naturaleza de los estados, los supuestos de declaración y las medidas extraordinarias a adoptar.

En nuestro derecho constitucional histórico, las diversas leyes de orden público a las que se remitían las constituciones en punto a la regulación de los estados excepcionales optaron por su concepción gradual como diversos estadios de intensidad creciente en función de la gravedad de las emergencias. La Ley de González Bravo de 1867 reguló de este modo los estados de alarma y de

\footnotetext{
${ }^{19}$ Los artículos 117.5 y 169 de la CE también hacen referencia, directa o tangencialmente, a los estados excepcionales. El primero remite a una ley para regular el ejercicio de la jurisdicción militar en el ámbito estrictamente castrense y en los supuestos de estado de sitio; el segundo prohíbe iniciar una reforma constitucional en tiempos de guerra o de vigencia de alguno de los tres estados excepcionales previstos en el artículo 116 de la CE.
} 
guerra; la Ley de Orden Público de 1870, el estado de prevención y alarma y el estado de guerra, y la Ley homónima de 1933, los estados de prevención, de alarma y de guerra ${ }^{20}$. Siguiendo este modelo, el informe de la Ponencia constitucional, hecho público en abril de 1978, se pronunció a favor de recoger "las tres situaciones excepcionales clásicas para graduar la mayor o menos intensidad de aquéllas" ${ }^{21}$. Y partidarios de la concepción gradual de los estados se mostraron también los portavoces centristas en los debates constituyentes celebrados en el Congreso de los Diputados, como fue el caso, singularmente, del diputado Cisneros Laborda al rechazar las enmiendas de supresión del estado de alarma presentadas por los diputados comunistas Solé Tura y Sánchez Montero, porque su aceptación "[...] abocaría al resultado paradójico de que, para la consideración de problemas de menor entidad, para situaciones conflictivas menos graves, se seguirían consecuencias mucho más penosas desde el punto de vista jurídico, al tener que recurrir a la declaración del estado de excepción con la suspensión de garantías que, en este caso, sí conlleva”"22. Así las cosas, el artículo 20 del proyecto de ley orgánica de seguridad ciudadana -convertido más tarde en proyecto de ley orgánica de los estados de alarma, excepción y sitio- pretendió configurar el estado de alarma como un instrumento para hacer frente a emergencias o catástrofes naturales y sanitarias, pero también como una suerte de primer grado o estadio con el que enfrentar emergencias político-sociales y "alteraciones del orden público o de la seguridad ciudadana". Y en consonancia con ello, el artículo 28 del proyecto sólo preveía la declaración del estado de excepción "cuando el orden público resultara tan gravemente alterado que el ejercicio de las potestades previstas en los artículos anteriores [relativos al estado de alarma] fuera insuficiente para restablecerlo o mantenerlo".

\footnotetext{
${ }^{20}$ La pluralidad de estados había sido una constante en la España constitucional, pero, a excepción de la mención del estado de guerra en la Constitución de 1931, nuestras constituciones se limitaron a regular la suspensión de derechos como eventual contenido de las situaciones excepcionales, delegando en el legislador de orden público la tarea de concretar los tipos de estados y su diferente naturaleza. Sobre los estados excepcionales en nuestra historia constitucional, FERNÁNDEZ SEGADO, F., El estado de excepción en el derecho constitucional español, Edersa, Madrid, 1977, pp. 92-102, 121-144 y 225-264, quien da cuenta, asimismo, de los estados de excepción y de guerra regulados bajo el franquismo en la Ley de Orden Público de 1959.

${ }^{21}$ Boletín Oficial de las Cortes, núm. 82, 17 de abril de 1978, p. 1574.

22 Diario de Sesiones del Congreso de los Diputados (DSCD), Comisión de Asuntos Constitucionales, núm. 84, 8 de junio de 1978, p. 3075.
} 
En la tramitación parlamentaria del proyecto se produjo, sin embargo, un significativo giro en la concepción gradual de ambos estados. El Informe de la Ponencia suprimió la mención a las crisis de orden público como supuesto habilitante del estado de alarma mutando su naturaleza y configuró el estado de excepción como una emergencia ante graves crisis de orden público que cabe declarar cuando el ejercicio de las potestades ordinarias resulte insuficiente para restablecer la normalidad. El Pleno de Congreso de los Diputados, por su parte, aprobó lo que sería la redacción definitiva de la Ley Orgánica 4/1981, de 1 de junio, de los estados de alarma, excepción y sitio (LOAES), en la que desapareció la cláusula abierta, meramente ejemplificativa, que enunciaba los presupuestos de hecho del estado de alarma y en la que, tras aceptar una enmienda in voce del grupo parlamentario comunista, se anuló en la práctica el supuesto de paralización de servicios públicos esenciales que justificaba su declaración al exigir que, simultáneamente, concurriera "alguna de las demás circunstancias contenidas en este artículo". Se consumó así la desnaturalización del estado de alarma como recurso frente a emergencias menos graves de naturaleza político-social y se consagró una lectura pluralista de nuestro derecho de excepción, en la que los tres estados fueron configurados como instrumentos distintos para emergencias sustancialmente distintas: "el estado de alarma -subrayó el senador socialista Morán Lópezpara unas situaciones que vienen de hechos naturales o sociales que ocurren en la historia; el estado de excepción para situaciones que afectan al orden público y que es previsible que no puedan atajarse por los medios ordinarios; y el estado de sitio ante procesos que afectan al orden constitucional"23. Nada avalaba, sin embargo, una opción tan rígida que prescindiera de la concepción bifronte del estado de alarma y de un posible uso gradual de los diversos estados, sino al contrario, como la regulación del estado de alarma y de los otros dos estados evidenciaba y alguna doctrina señaló ${ }^{24}$. Este fue el principal

\footnotetext{
${ }^{23}$ Diario de Sesiones del Senado (DSS), núm. 105, de 14 de mayo de 1981, p. 5312.

${ }^{24}$ El legislador no pudo evitar en su regulación la lógica gradualista consustancial a los estados de menor gravedad constitucional. Como J. M SERRANO ALBERCA subrayó, "si bien existe una diferencia cualitativa entre los tres estados, esta diferencia no los convierte en compartimentos estancos, absolutamente diferentes, sino que todos están unidos por la excepcionalidad y entre ellos puede descubrirse un gradualismo que se [...] pone de manifiesto tanto por la interrelación de las situaciones como por las medidas empleadas -previstas- para contrarrestarlas". Cfr. "Comentario al artículo 116", en GARRIDO FALLA, F. (dir.), Comentarios a la Constitución, 3ª . Ed., Civitas, Madrid, 2001, p. 1776.
} 
error del legislador y es el primer defecto de lege lata, como la puesta en práctica de nuestro derecho de excepción ha venido a confirmar.

Tras la aprobación de la LOAES, en fin, el estado de alarma quedó formalmente configurado como una situación excepcional reservada para afrontar catástrofes o calamidades naturales, crisis sanitarias, situaciones de desabastecimiento de productos de primera necesidad y supuestos de paralización de servicios públicos esenciales en los que no se garanticen los servicios mínimos y sólo cuando concurra al tiempo alguna de las demás emergencias anteriormente citadas (art. 4 de la LOAES). Por su parte, el estado de excepción pasó a ser un instrumento específico para hacer frente, sin necesidad de previa declaración de alarma, a graves afecciones del libre ejercicio de los derechos y libertades de los ciudadanos, del normal funcionamiento de las instituciones democráticas, del mantenimiento de los servicios públicos esenciales para la comunidad, o de cualquier otro aspecto del orden público, cuando el ejercicio de las potestades ordinarias fuera insuficiente para restablecerlos o mantenerlos (art. 13 de la LOAES). EI estado de sitio, finalmente, cuya gestión se encomienda, bajo la dirección del Gobierno, a la autoridad militar, quedó reservado para las graves crisis de Estado, cuando se produzca o amenace producirse una insurrección o acto de fuerza contra la soberanía o independencia de España, contra su integridad territorial o contra el ordenamiento constitucional que no pueda resolverse por otros medios (art. 32.1 de la LOAES). Así quedaba configurado el proyecto normativo regulador de la excepción. Tan sólo faltaba que su vigencia latente fuera activada por la concurrencia de alguna de las emergencias previstas.

III. EL DERECHO DE EXCEPCIÓN EN ACCIÓN: SUS RIGIDICES, INSUFICIENCIAS Y LAGUNAS BAJO LOS ESTADOS DE ALARMA DECLARADOS EN ESPAÑA EN 2010 Y 2020

Durante tres décadas, ningún estado fue declarado. Pese a acaecer calamidades naturales, catástrofes medioambientales como la del buque Prestige y graves atentados terroristas, como el perpetrado el 11 de marzo de 2004, la LOAES mantuvo una vigencia latente. Los estados de excepción y de sitio fueron considerados recursos de otros tiempos felizmente superados. $Y$ el estado de alarma fue calificado por la doctrina como un instrumento de dudosa 
utilidad. Frente a las crisis naturales, sanitarias o tecnológicas, la legislación sectorial ordinaria ya preveía medidas extraordinarias que hacían innecesario recurrir a la declaración de dicho estado ${ }^{25}$. Y las prevenciones introducidas en su regulación legal dificultaban su uso como primer estadio o grado ante las situaciones de conflictividad social que no precisaran, por su menor gravedad, la suspensión de derechos ${ }^{26}$. No resulta extraño, por ello, que la doctrina llegara a hablar de la desuetudo de nuestro derecho constitucional de excepción, cuya única función consistía básicamente en "estar ahí, determinando por defecto todo lo que no se podía hacer, ni aun invocando la salus publica", ${ }^{27}$.

En diciembre de 2010, sin embargo, la realidad excepcional se encargó de evidenciar lo errónea que era esta tesis, haciendo necesaria la declaración del estado de alarma para restablecer el servicio esencial del transporte aéreo boicoteado por los propios controladores, quienes abandonaron concertadamente sus puestos de trabajo en las torres de control. $Y$ sendos estados de alarma han sido nuevamente declarados en marzo y octubre de 2020 para hacer frente a la grave emergencia de salud pública ocasionada por la pandemia de la COVID-19, cuando las medidas previstas en la legislación sanitaria ordinaria, como la Ley Orgánica de Medidas Especiales en Materia de Salud Pública y la Ley General de Salud Pública, resultaban absolutamente insuficientes para reducir la extensión de los contagios. En ambas ocasiones, el estado de alarma ha demostrado ser un instrumento excepcional eficaz, pero su declaración y su contenido suscitaron abundantes críticas. En diciembre de

\footnotetext{
25 "[EI] arsenal de disposiciones -señaló R. MATEU-ROS Y CEREZO- que contemplan las más variadas situaciones de emergencia administrativa sin necesidad de los requisitos que supone la declaración del estado de alarma, ha vaciado este último de contenido propio, excepto en relación con aquellos fenómenos que, siendo inscribibles en la relación de presupuestos materiales que antes veíamos, carezcan de reglamentación especial. Obsérvese, además, que la técnica del decreto-ley permite al Ejecutivo adoptar ante situaciones de esta naturaleza las medidas de urgencia que requieran rango legal sin necesidad tampoco de acudir al estado de alarma (como ocurrió en las inundaciones de Valencia de octubre de 1982)". Cfr. "Estados de alarma, excepción y sitio", en VV.AA., Gobierno y Administración en la Constitución, vol. I, Instituto de Estudios Fiscales, Madrid, 1988, pp. 175-176. En el mismo sentido, A. CARRO MARTÍNEZ, quien llegó a afirmar que "el estado de alarma y la nada son la misma cosa". Cfr. "Artículo 116. Situaciones de anormalidad constitucional", en ALZAGA VILLAAMIL, O. (dir.), Comentarios a la Constitución española de 1978, tomo IX, Edersa-Cortes Generales, Madrid, 1998, p. 253.

${ }^{26}$ CRUZ VILLALÓN, P., Estados excepcionales y suspensión de garantías, cit., pp. 70-71.

27 En este sentido, CRUZ VILLALÓN, P., "Veinticinco años de normalidad constitucional", Revista de Derecho Político, núms. 58-59, 2003-2004, pp. 22-23 y, del mismo autor, "Normalidad y excepción", Revista Española de Derecho Constitucional, núm. 71, 2004, p. 192.
} 
2010, los afectados por la declaración y parte de la doctrina adujeron que no concurrían los supuestos legales para su activación y que la militarización decretada en los centros de control de tránsito aéreo había suspendido derechos fundamentales de los controladores ${ }^{28}$. En 2020, se arguyó que la severísima restricción de la libertad de circulación, el confinamiento domicilio impuesto y la prohibición de actividades grupales excedían las medidas susceptibles de adoptar bajo el estado de alarma ${ }^{29}$. En ambas ocasiones se sostuvo que, en lugar de declararse el estado de alarma, debía haberse declarado el estado de excepción por concurrir sus supuestos de hecho y por adoptarse medidas que sólo cabían a su amparo. En ambas, la autoridad que corresponde al Gobierno fue delegada en otras autoridades estatales y/o autonómicas no previstas en el artículo 7 de la LOAES, lo que suscitó el reproche de la doctrina. En ambas, se solicitó la prórroga del estado de alarma por períodos más largos que el periodo de declaración: del 20 de diciembre de 2010 al 15 de enero de 2011, en el estado declarado para normalizar el trasporte aéreo, y del 9 de noviembre de 2020 al 9 de mayo de 2021, en el estado declarado para enfrentar la segunda ola de contagios de la COVID-19, una prórroga considerada exorbitante. $\mathrm{Y}$ en ambas, en fin, se ha dudado del órgano competente para proceder al control jurisdiccional de los decretos de

${ }^{28}$ VIDAL PRADO, C. y DELGADO RAMOS, D., "Algunas consideraciones sobre la declaración del estado de alarma y su prórroga", Revista Española de Derecho Constitucional, núm. 92, 2011, pp. 253-255; ABA CATOIRA, A., "El estado de alarma en España", Teoría y realidad constitucional, núm. 28, 2011, pp. 335-336; REQUEJO RODRÍGUEZ, P., "Teoría vs. práctica del estado de alarma en España", en VV.AA. Constitución y democracia: ayer y hoy. Libro homenaje a Antonio Torres del Moral, vol. 2, Universitas, Madrid, 2012, pp. 1502-1503; SEDANO LORENZO, A., El estado de alarma y la justicia militar. A propósito de la crisis de controladores aéreos, Liber Factory, Madrid, 2015, pp. 80-84, y SIEIRA MUCIENTES, S., "Los estados excepcionales", Revista de las Cortes Generales, núm. 104, 2018, pp. 376-378.

${ }^{29}$ ARAGÓN REYES, M., "Hay que tomarse en serio la Constitución", El País, 10 de abril de 2020 (disponible en https://elpais.com/elpais/2020/04/09/opinion/1586420090_736317.html); DÍAZ REVORIO, F. J., "A vueltas con la suspensión de los derechos fundamentales", Almacén de derecho, 9 de abril de 2020 (disponible en https://almacendederecho.org/a-vueltas-con-lasuspension-de-los-derechos-fundamentales/); NOGUEIRA LÓPEZ, A., "Confinar el coronavirus. Entre el viejo derecho sectorial y el derecho de excepción", y AMOEDO-SOUTO, C. A., "Vigilar y castigar el confinamiento forzoso. Problemas de la potestad sancionadora al servicio del estado de alarma sanitaria", ambos en El Cronista del Estado Social y Democrático de Derecho, núms. $86-87,2020$, p. 27 y p. 66, respectivamente. (disponible en http://www.elcronista.es/El-Cronista-n\%C3\%BAmero-86-87-Coronavirus.pdf); $\quad$ CUENCA MIRANDA, A., "Alarma excepcional", Papeles FAES, núm. 236, 2020, pp. 3-6 (disponible en https://fundacionfaes.org/file_upload/news/pdfs/20200323130208.pdf); ALBAR GARCíA, J. "Estado de excepción encubierto", El español, 18 de abril de 2020 (disponible en https://www.elespanol.com/opinion/tribunas/20200418/excepcion-

encubierto/483321669_12.html), y SIEIRA MUCIENTES, S., "Estado de alarma", Eunomía: Revista en Cultura de la Legalidad, núm. 19, 2020, pp. 292-297. 
declaración y de prórroga. Todo ello ha evidenciado las limitaciones, inconsistencias y lagunas de nuestro derecho de excepción.

El legislador de la LOAES mudó la relación enunciativa de los supuestos habilitantes del estado de alarma en una pretendidamente cerrada y anuló como supuesto autónomo de declaración la paralización de los servicios públicos esenciales para la comunidad a fin de evitar su utilización ante conflictos sociales provocados por el abuso de derechos o el incumplimiento de deberes. La realidad, sin embargo, se ha encargado de evidenciar el error cometido y el vano intento de pretender anular la lógica gradualista consustancial a los estados excepcionales de menor gravedad. Conforme a la absurda redacción del artículo 4.c) de la LOAES, la declaración del estado de alarma en diciembre de 2010 no procedía, en efecto, porque no concurrió al tiempo ninguna otra de las emergencias que la habrían justificado ex lege. Pero la misma doctrina que subrayó su improcedencia ha reconocido, al amparo de los principios de urgencia, necesidad y proporcionalidad, que el estado de excepción -supuestamente el estado que a su juicio debía haberse declaradohabría llegado tarde y habría resultado igualmente inadecuado. "[...] esta vía -afirmaron Vidal Prado y Delgado Ramos refiriéndose al estado de excepción- habría abierto todavía más incertidumbres, y hubiera sido muy complicada de tomar de modo urgente. Habría sido necesario convocar al Congreso de los Diputados el mismo sábado 4 de diciembre, lo cual habría retrasado todo el operativo de un modo que probablemente acabaría por hacer inútil la medida. Pero, además, se trataría ya de una declaración que llevaría consigo una suspensión de derechos, de mucha mayor gravedad; vía, además, de difícil defensa política y social, por lo que no parecía adecuado optar por ella,"30.

\footnotetext{
${ }^{30}$ VIDAL PRADO, C. y DELGADO RAMOS, D., "Algunas consideraciones sobre la declaración del estado de alarma y su prórroga", cit., p. 255. En el mismo sentido, SIEIRA MUCIENTES, S., "Los estados excepcionales", cit., pp. 378 y 390.

Mucho tiempo antes, alguna doctrina criticó el fárrago, la dilación y la complicación innecesarios que supone la exigencia de autorización parlamentaria para que el Gobierno pueda declarar el estado de excepción, tanto por razones de técnica legislativa como por razones de eficacia. Y advirtió del riesgo de convertir dicho estado en un recurso impracticable para afrontar de modo urgente las emergencias para las que está previsto, forzando en su lugar de modo extrajurídico el recurso al estado de alarma. Ello podía haberse evitado si el constituyente hubiera habilitado directamente al Gobierno para declarar también el estado de excepción, sin perjuicio del posterior control parlamentario y de la autorización, en su caso, de su prórroga. Véanse, ALZAGA VILLAAMIL, O., Comentario sistemático a la Constitución española de 1978, Ediciones del Foro, Madrid, 1978, p. 699; FERNÁNDEZ SEGADO, F., "La
} 
La literalidad del artículo 4 LOAES respecto a los supuestos habilitantes de la declaración del estado de alarma podía ser superada, como hemos sostenido en otro lugar, mediante una interpretación constitucionalmente conforme a la irreductible naturaleza bifronte del estado de alarma ${ }^{31}$. Atendiendo a la imprevisibilidad de la excepción, la relación de los supuestos del estado de alarma no debería considerarse taxativa y su activación no debería quedar limitada a la concurrencia de catástrofes o calamidades naturales, crisis sanitarias y situaciones de desabastecimiento, sino admitirse también frente a las alteraciones menos graves del orden público o la paz social que puedan resolverse sin recurrir a la suspensión de derechos. Así lo ha postulado alguna doctrina $^{32}$, pero si queremos que el derecho de excepción siga siendo derecho y no se disuelva en la facticidad, el legislador debe aprovechar las lecciones que la excepción ha deparado. $\mathrm{Y}$ recuperar de lege ferenda la relación ejemplificativa y abierta de los supuestos habilitantes del estado de alarma del proyecto originario, asumir normativamente su doble naturaleza -como emergencia distinta, pero también como primer estadio frente a crisis de menor gravedad- y clarificar su operatividad ante apremiantes situaciones de conflictividad social, como la desencadenada por los controladores aéreos en 2020.

La LOAES también tipifica las medidas aplicables bajo cada estado, pero, dado el carácter imprevisible de las situaciones de emergencia y su diversa naturaleza, la capacidad para regular apriorísticamente las respuestas adecuadas a las circunstancias ha resultado ser muy limitada. En ambos estados de alarma, las restricciones han ido más allá de las previstas expresamente por el legislador y han evidenciado la tenue línea existente entre

Ley Orgánica de los estados de alarma, excepción y sitio", Revista de Derecho Político, núm. 11, 1981, p. 103. y SANTAOLALLA LÓPEZ, F., Derecho parlamentario español, Espasa-Calpe, Madrid, 1990, pp. 373-374.

${ }^{31}$ GARRIDO LÓPEZ, C., "La naturaleza bifronte del estado de alarma y el dilema limitaciónsuspensión de derechos", Teoría y realidad constitucional, núm. 46, 2020, pp. 386-388.

${ }^{32}$ En este sentido, FERNÁNDEZ SEGADO, F., "La Ley Orgánica de los estados de alarma, excepción y sitio", cit., p. 95, GARCÍA CUADRADO, A. M., "El estado de alarma y su ambigua naturaleza", Cuadernos Constitucionales de la Cátedra Fadrique Furió Ceriol, núm. 8, 1994, p. 85, quien sustenta su opinión en la voluntad del constituyente, y GOIG MARTíNEZ, J. M., "La defensa política de la Constitución. Constitución y estados excepcionales. (II) Un estudio de derecho constitucional comparado", Revista de Derecho UNED, núm. 5, 2009, p. 225, para quien el estado de alarma "responde a la doble necesidad de constituir un instrumento frente a catástrofes naturales y situaciones de anormalidad social [...] que perturben el normal desenvolvimiento de la vida social del país". 
la limitación y la suspensión de derechos. En teoría, la delimitación entre ambas categorías es posible. La suspensión, ha sostenido Aláez Corral, conllevaría una suerte de "desconstitucionalización" que dejaría sin efecto parcial o totalmente la obligatoriedad jurídica de un derecho fundamental. La limitación, en cambio, incide sobre su haz de facultades y puede llegar a la "negación transitoria del ejercicio del derecho a su titular", pero no desplaza su régimen jurídico, que continúa vigente, ni elimina sus garantías ${ }^{33}$. En la práctica, sin embargo, resulta muy difícil distinguir dónde termina la limitación o restricción de derechos proporcionada a las circunstancias y dónde empieza una suspensión constitucionalmente reservada a los estados de excepción y sitio. Y el problema es especialmente delicado en el caso de las medidas extraordinarias de limitación de la libertad de circulación, de intervención de empresas y servicios y de movilización de su personal que autorizan los artículos 11.a) y 12.2 de la LOAES.

En el estado de alarma de 2010 se consideraron excesivas la movilización de los controladores aéreos y su sumisión a las leyes penales y disciplinarias militares, aunque, sin dicha militarización, las órdenes del jefe del Estado Mayor del Ejército del Aire no habrían surtido ningún efecto. En el estado de alarma declarado en marzo de 2020, se ha criticado, por su parte, la intensidad de las restricciones de la libertad circulatoria, el confinamiento domiciliario y la extrema limitación de las relaciones grupales, que produjeron la afectación en cadena de otros derechos, como los de reunión y manifestación, la libertad de cultos y la libertad de empresa.

En opinión de alguna doctrina, que compartimos, ninguna de las citadas medidas excepcionales supuso una auténtica suspensión de derechos. En 2010, los controladores aéreos incurrieron en un flagrante incumplimiento de deberes y vulneraron derechos fundamentales de terceros. Su boicot paralizó un servicio público esencial. Y, para restablecerlo, el estado de alarma permite, además de la movilización ex el artículo 8.5 del anterior Código Penal Militar y del artículo 2.5 del actualmente vigente, imponer prestaciones obligatorias e impartir las órdenes necesarias para garantizar el funcionamiento de los

\footnotetext{
${ }^{33}$ ALÁEZ CORRAL, B., "El concepto de suspensión general de los derechos fundamentales", en LÓPEZ GUERRA, L. y ESPÍN TEMPLADO, E. (coords.), La defensa del Estado, Tirant lo Blanch, Valencia, 2004, p. 235. Véase, asimismo, REQUEJO RODRÍGUEZ, P., "¿Suspensión o supresión de los derechos fundamentales?", Revista de Derecho Político, núm. 51, 2001, pp. 112-113.
} 
servicios afectados (art. 11 LOAES), lo que supone que el ejercicio del derecho de huelga queda supeditado al restablecimiento del servicio, pero no suspendido, porque sus garantías normativas y procesales continuaron intactas y los controladores pudieron impetrar su tutela ${ }^{34}$. En 2020, las medidas extraordinarias adoptadas para hacer frente a la crisis sanitaria resultaron tan duras que, como subrayó Cruz Villalón, difícilmente cabía encontrarlas acabadamente reflejadas en ninguno de los estados de emergencia previstos, ni describirlas "con arreglo a las categorías constitucionales disponibles", pero, con todo, la mayoría de la doctrina ha considerado que la limitación de la libertad de circulación y de empresa fue proporcionada y que el artículo 7 del Decreto 463/2020, de 14 de marzo, previó las suficientes excepciones a la prohibición general de circular por vías públicas como para considerarla una medida compatible con el régimen jurídico del estado de alarma. La restricción de la libertad deambulatoria y el confinamiento impuesto, señaló De la Quadra-Salcedo, "constatan un hecho -la universal capacidad de propagar la enfermedad, imposible de individualizar- que delimita automáticamente la frontera de nuestros derechos con nuestra obligación de no hacer daño a los demás"36. Ambas medidas persiguen salvaguardar "otros derechos fundamentales (en primer lugar, el derecho a la vida del art. 15 CE) u otros derechos 0 bienes constitucionales (destacadamente, el derecho a la protección de la salud del art. 43.1 CE, y la tutela de la salud pública del art. 43.

\footnotetext{
${ }^{34}$ MARTÍNEZ CUEVAS, Ma. D., "El estado de alarma y el derecho fundamental de huelga: el caso de los controladores civiles de tránsito aéreo en España", Trabajo y derecho, núm. 64, 2020 , p. 3. "Al ser la huelga un derecho limitado -subrayó A. M. GARCíA CUADRADO- la normativa legal que lo regula prevé no sólo los llamados decretos de servicios mínimos sino una serie de intervenciones administrativas de naturaleza coercitiva para evitar males graves al conjunto de la sociedad. De ahí que, en principio, las medidas previstas no deban considerarse como suspensión del derecho de huelga, sino como limitaciones al mismo, y por tanto permitidas para tiempo de normalidad y durante el estado de alarma". Cfr. "El estado de alarma y su ambigua naturaleza", cit., p. 99.

${ }^{35}$ CRUZ VILLALÓN, P., "La Constitución ante el estado de alarma", El País, 17 de abril de 2020 (https://elpais.com/elpais/2020/04/16/opinion/1587025782_733659.html). "Nuestro ordenamiento jurídico -afirmó en el mismo sentido J. BARNES-, como el de tantos otros países, no estaba preparado para hacer frente a esta pandemia. El estado de alarma se quedaba corto; el de excepción, largo. [...] Las medidas que ofrece nuestro Derecho son, en cierto modo, insuficientes e imperfectas. Y, sin embargo, "con estos bueyes hay que arar»". Cfr. "Un falso dilema", El País, 14 de agosto de 2020 (https://elpais.com/opinion/2020-08-13/unfalso-dilema.html).

${ }^{36}$ DE LA QUADRA-SALCEDO, T., "Límite y restricción, no suspensión", El País, 8 de abril, 2020 (https://elpais.com/elpais/2020/04/07/opinion/1586245220_558731.html).
} 
$2 \mathrm{CE}$ ), igualmente merecedores de protección",37. Y esas restricciones pueden considerarse idóneas, necesarias y proporcionadas en sentido estricto al superar los beneficios reportados a los perjuicios inferidos a las libertades de circulación y empresa, como subrayó el Defensor del Pueblo en funciones en su Resolución sobre las solicitudes de recurso de inconstitucionalidad contra el Real Decreto 463/2020, de 14 de marzo, y sus prórrogas, dirigidas a la institución, adoptada el 3 de septiembre de $2020^{38}$.

La pandemia, reconoció el ATC 40/2020, de 30 de abril, revistió por sus efectos "dimensiones desconocidas hasta la fecha [...] y, desde luego, imprevisibles cuando el legislador articuló la declaración de los estados excepcionales en el año 1981" (FJ 4). Pero la interpretación y la ponderación para salvar las carencias de la LOAES tienen su límite si pretendemos salvaguardar su normatividad. De lege ferenda, se debería incluir por ello un nuevo elenco de medidas modulable en función de la gravedad de las emergencias, precisar las existentes y delimitar su alcance, especialmente en punto a las limitaciones de la libertad circulatoria, la intervención de industrias y servicios y la movilización de su personal. Debemos ser conscientes, sin embargo, de los condicionamientos que arrostra este empeño. Surgida la emergencia, el legislador intentará codificarla, pero difícilmente podrá imaginar cuál será la siguiente y qué medidas se precisarán para superarla ${ }^{39}$. La indeterminación, las

\footnotetext{
${ }^{37}$ ARROYO GIL, A., “¿Estado de alarma o estado de excepción?”, Agenda Pública, 12 de abril de 2020 (http://agendapublica.elpais.com/estado-de-alarma-o-estado-de-excepcion/). En el mismo sentido, LEIVA ESCUDERO, G., "Constitucionalidad de las restricciones a la libertad de circulación en el estado de alarma por el coronavirus Covid-19", Diario La Ley, núm. 9636, 20 de mayo de 2020, p. 20.

(https://diariolaley.laleynext.es/Content/Documento.aspx?params=H4sIAAAAAAAEAMtMSbF1 CTEAAmMDSzMjQ7Wy1KLizPw8WyMDIwMDU0OwQGZapUt-

ckhlQaptWmJOcSoAf7GZ3jUAAAA=WKE); CARRILLO LÓPEZ, M., "Derecho de excepción y garantía de los derechos en tiempos de pandemia", LEGAL. Revista del Parlamento Vasco, núm. 1, 2020, pp. 81-83. y BARRERO ORTEGA, A., "Estado de alarma y restricción de derechos fundamentales", en CERDEIRA BRAVO DE MANSILLA, G. (dir.), Coronavirus y derecho en estado de alarma, Reus Editorial, Madrid, 2020, pp. 132-133.

${ }^{38}$ Resolución del Defensor del Pueblo (e. f.) adoptada en relación con las 617 solicitudes de recurso de inconstitucionalidad contra el Real Decreto 463/2020, de 14 de marzo, por el que se declara el estado de alarma para la gestión de la situación de crisis sanitaria ocasionada por la COVID-19 y sus prórrogas, de 3 de septiembre de 2020, p. 21. Disponible en: https://www.defensordelpueblo.es/wp-content/uploads/2020/09/resolucion_estado_alarma.pdf.

${ }^{39}$ GARCIA ROCA, F. J., "El control parlamentario y otros contrapesos del Gobierno en el estado de alarma: la experiencia del coronavirus", en BARCELÓ ROJA, D.; DÍAZ RICCI, S.; GARCÍA ROCA, J. y GUIMARÁES TEIXEIRA, Ma. E. (coords.), COVID-19 y parlamentarismo. Los parlamentos en cuarentena, Universidad Autónoma Nacional de México e Instituto de Derecho Parlamentario, México, 2020, p. 21-22.
} 
fundación

Manuel Giménez Abad

deEstudios Parlamentarios ydelEstadoAutonómico

cláusulas generales y las omisiones del derecho de excepción seguirán siendo por ello inevitables. Como lo será a la postre el recurso a los principios de necesidad y proporcionalidad para superarlas.

Al amparo del artículo 7 de la LOAES, la autoridad competente para ejecutar las medidas autorizadas bajo los estados de alarma debería ser el Gobierno o, por delegación suya, el presidente de la Comunidad Autónoma afectada exclusivamente por la emergencia. En el estado de alarma sanitaria declarado mediante Real Decreto 900/2020, de 9 de octubre (BOE núm. 268 de 9 de octubre de 2020), y delimitado territorialmente a varios municipios de la Comunidad Autónoma de Madrid, la única autoridad competente fue el Gobierno de la Nación (art. 4). Pero en los estados de alarma declarados en diciembre de 2010, en la primavera de 2020 y en octubre de 2020, la autoridad del Gobierno fue delegada en otras autoridades estatales o autonómicas. En el Real Decreto 1673/2010, de 4 de diciembre, el Gobierno delegó su autoridad en el jefe del Estado Mayor del Ejército del Aire (art. 6). En el Real Decreto 463/2020, de 14 de marzo, de declaración del estado de alarma para la gestión de la crisis sanitaria de la COVID-19, y sus cuatro primeras prórrogas, la autoridad se delegó en los ministros de Sanidad, Defensa, Interior y Transportes, Movilidad y Agenda Urbana, bajo la superior dirección del presidente del Gobierno (art. 4.2). En la quinta prórroga de dicho estado de alarma, aprobada mediante Real Decreto 537/2020, de 22 de mayo (BOE núm. 143, de 23 de mayo), la única autoridad competente delegada fue el ministro de Sanidad, bajo la superior dirección del presidente del Gobierno y con arreglo al principio de cooperación con las comunidades autónomas. En el Real Decreto $555 / 2020$, de 5 de junio, que prorrogó por sexta vez el estado de alarma declarado el 14 de marzo (BOE núm. 159, de 6 de junio), la delegación se amplió a los presidentes de las CC.AA. "para la adopción, supresión, modulación y ejecución de medidas correspondientes a la fase III del plan de desescalada" (art. 6). Y en Real Decreto 926/2020, de 25 de octubre, de declaración de un nuevo estado de alarma para hacer frente a la segunda ola de contagios (BOE núm. 282, de 25 de octubre) y su larga prórroga, la autoridad se ha delegado íntegramente en los presidentes de las CC.AA. y de las ciudades autónomas de Ceuta y Melilla, quienes han sido habilitados para dictar las órdenes, resoluciones y disposiciones para la aplicación de lo previsto en los artículos 5 a 11 del mismo (art. 2.2) y para modular, flexibilizar y 
suspender la aplicación de las medidas previstas en los artículos 6,7 y 8 del Decreto (art. 10). Dichas delegaciones han suscitado el reproche de la doctrina por no estar previstas en la LOAES. Y especialmente criticada ha sido la última delegación, aunque no tanto por potenciar el papel de las comunidades autónomas en la ejecución de medidas que inciden sobre materias de su competencia en situaciones de normalidad, lo que habían defendido algunos autores $^{40}$, sino por la falta de fijación de los criterios en virtud de los cuales se pueden limitar derechos y por la discrecionalidad que se otorga a los presidentes autonómicos para hacer efectivas, o no, dichas limitaciones ${ }^{41}$. Lo que ha provocado una arbitraria segmentación territorial de las medidas restrictivas de derechos y la indeseable "balcanización" del estado de alarma.

La prórroga del estado de alarma no está sometida legalmente a término, por lo que corresponde al Congreso, a propuesta del Gobierno, pronunciarse sobre su duración, que ha de quedar fijada en el correspondiente decreto de prórroga. El Real Decreto 1717/2010, de 17 de diciembre, prorrogó el estado de alarma veintisiete días. Durante la vigencia del estado de alarma declarado el 14 de marzo de 2020 para gestionar la situación de crisis sanitaria ocasionada por la COVID, las sucesivas prórrogas tuvieron una duración de

\footnotetext{
${ }^{40}$ Las medidas que pueden ser adoptadas bajo el estado de alarma recaen mayoritariamente sobre materias de competencia autonómica, lo que, como señaló J. PORRES AZCONA, conduce "[...] a una consideración lógica: si son las Comunidades Autónomas quienes disponen, a través de sus órganos propios, de los elementos de conocimiento de la situación y de la capacidad de movilizar recursos, el normal funcionamiento de los servicios a fin de restablecer la tranquilidad ciudadana requiere que sean las autoridades comunitarias quienes actúen en el campo de unas competencias que, además, en situación de normalidad son gestionadas y dirigidas por ellas mismas". Cfr. "La decisión sobre poderes excepcionales", cit., p. 61. En este sentido, en relación con la crisis sanitaria de la COVID-19, DOMÉNECH PASCUAL, G. ha afirmado que "la Administración General del Estado carece de las estructuras organizativas, los medios personales, la experiencia y los conocimientos necesarios para gestionar de manera hipercentralizada una crisis sanitaria de la envergadura de la del coronavirus. Tras el proceso de transferencia de competencias producido hace ya tiempo, esos recursos están fundamentalmente en manos de las Comunidades autónomas, que tienen mejores recursos personales, información y seguramente incentivos que el Estado para gestionar esta crisis sanitaria con acierto". Cfr. "La discutible prórroga del estado de alarma", Almacén de Derecho, 17 de mayo de 2020 (https://almacendederecho.org/la-discutibleprorroga-del-estado-de-alarma).

${ }^{41}$ Por todos, HERBÓN COSTAS, J. J., "El mando y gestión del estado de alarma", en BIGLINO CAMPOS P. y DURÁN ALBA, J. F. (dirs.), Los efectos horizontales de la COVID-19 sobre el sistema constitucional: estudios sobre la primera oleada, cit., pp. 94-96 y 101-108; TAJADURA TEJADA, J., "Estado de alarma y seguridad jurídica", El País, 27 de octubre de 2020(https://elpais.com/opinion/2020-10-26/estado-de-alarma-y-seguridad-juridica.html), y RUIZ ROBLEDO, A., "El estado de alarma: donde quiere el gobernante", El País, 6 de noviembre de 2020 (https://elpais.com/opinion/2020-11-05/el-estado-de-alarma-donde-quiereel-gobernante.html).
} 
quince días. Tras declarar nuevamente el estado de alarma para hacer frente al repunte de contagios de la segunda ola mediante el Real Decreto 256/2020, de 25 de octubre, el Gobierno optó en esta ocasión, sin embargo, por solicitar al Congreso de los Diputados una prórroga de seis meses, hasta el 9 de mayo de 2021. Dicha prórroga, con la que el Ejecutivo pretendía evitar el desgaste al que se vio sometido en las negociaciones de las citadas prórrogas de quince días, fue autorizada por el Congreso y formalizada mediante Real Decreto 956/2020, de 3 de noviembre, pero ha sido muy criticada por alguna doctrina. A su juicio, las prórrogas deberían tener idéntico plazo que la declaración a fin de posibilitar periódicamente el pronunciamiento de la Cámara sobre el mantenimiento de las condiciones excepcionales que justifican el estado. "Garantía que -en palabras de Aragón Reyes- no puede quedar a la libre disposición de la mayoría de la Cámara, entre otras razones porque entonces se hurtaría a la minoría su derecho al ejercicio del control parlamentario, y a la opinión pública el conocimiento del debate que, sobre la prórroga, en la Cámara habrá de realizarse" ${ }^{\text {"2 }}$. Pero, como otra doctrina ha subrayado, el silencio que la CE y la LOAES no guardan cuando se refieren a la prórroga del estado de excepción, bien podría entenderse como permisivo, no prohibitivo, de que la duración de la prórroga fuera mayor del plazo de su declaración. A juicio de García Roca, "las prohibiciones deben ser expresas y no inferidas de juicios lógicos. No hay plazo legal y, si la prórroga pasa a ser una disposición del Parlamento, la mayoría tiene discrecionalidad y el resultado, plena legitimidad democrática” ${ }^{43}$.

Como referí supra, pese a las limitaciones existentes, los ordenamientos constitucionales más avanzados garantizan el control jurisdiccional de las decisiones de declaración y de prórroga de los estados excepcionales. En unos casos, ante la jurisdicción contencioso-administrativa; en otros, ante la justicia constitucional. El problema en España es que este control no ha sido previsto

\footnotetext{
${ }^{42}$ ARAGÓN REYES, M., "Epílogo", en BIGLINO CAMPOS, P. y DURÁN ALBA, J. F. (dirs.), Los efectos horizontales de la COVID-19 sobre el sistema constitucional: estudios sobre la primera oleada, cit., p. 569. De la misma opinión, RUIZ ROBLEDO, A., "El estado de alarma: donde quiere el gobernante", El País, 6 de noviembre de 2020 (https://elpais.com/opinion/2020-1105/el-estado-de-alarma-donde-quiere-el-gobernante.html).

${ }^{43}$ GARCIA ROCA, F. J., "El control parlamentario y otros contrapesos del Gobierno en el estado de alarma: la experiencia del coronavirus", cit., p. 25. En el mismo sentido, DOMÉNECH PASCUAL, G., "La discutible prórroga del estado de alarma", Almacén de Derecho, 17 de mayo de 2020 (https://almacendederecho.org/la-discutible-prorroga-del-estado-de-alarma).
} 
ni constitucional, ni legalmente. Y la academia ha discrepado tanto de su viabilidad como del órgano jurisdiccional al que encomendarlo. Ello se ha debido a la diversa formalización jurídica (decretos en el caso de los estados de alarma y de excepción y resoluciones parlamentarias en el caso de sitio) y a la singular naturaleza de estas decisiones excepcionales, cuyo procedimiento de adopción en el caso del estado de alarma es muy distinto según se trate de la declaración del estado, que decide unilateralmente el Gobierno, o de su prórroga, que precisa autorización del Congreso de los Diputados siendo éste quien determina su alcance y condiciones. A juicio de alguna doctrina, el decreto de declaración sería una disposición reglamentaria revisable por la justicia administrativa; el decreto de prórroga, en cambio, formalizaría una decisión parlamentaria tan sólo controlable por la justicia constitucional ${ }^{44}$. Pero otra doctrina ha defendido que ambos decretos tendrían la misma naturaleza independientemente de su diversa gestación. Para algunos, ambos deberían ser considerados reglamentos sometidos al principio de legalidad y al control de la jurisdicción ordinaria ${ }^{45}$. Para otros, tanto la declaración como la prórroga son decisiones directamente incardinadas en la CE y, dado su carácter primario y efectos, su control debe reservarse a la jurisdiccional constitucional $^{46}$.

El problema trascendió el plano teórico tras la declaración y la prórroga del estado de alarma de 2010, cuyos correspondientes decretos fueron recurridos por los controladores aéreos ante la jurisdicción contencioso-administrativa. Inadmitidos dichos recursos con el argumento de su convalidación parlamentaria como causa de la falta de jurisdicción, los demandantes recurrieron en amparo la autorización de la prórroga y, más tarde, también en amparo, los autos del Tribunal Supremo que inadmitieron los recursos

\footnotetext{
${ }^{44}$ ARAGÓN REYES, M., "Acto con fuerza de ley", en ARAGÓN REYES, M. (coord.), Temas básicos de Derecho Constitucional, tomo I, Civitas, Madrid, 2001, p. 342 y NAVAS CASTILLO, A., "Los estados excepcionales y su posible control por el Tribunal Constitucional", Revista de la Facultad de Derecho de la Universidad Complutense, núm. 87, 1997, pp. 158-163.

${ }^{45}$ En este sentido, CRUZ VILLALÓN, P., "El nuevo derecho de excepción", Revista Española de Derecho Constitucional, núm. 2, 1981, pp. 115-116; LAFUENTE BALLE, J. M., "Los estados de alarma, excepción y sitio (II)", Revista de Derecho Político, núm. 31, 1990, pp. 34 y 42; REQUEJO RODRÍGUEZ, P., "Teoría vs. práctica del estado de alarma en España", cit., pp. 1512-1513.

${ }^{46}$ MATEU-ROS Y CEREZO, R., "Estados de alarma, excepción y sitio", cit., p. 195; GARCíA CUADRADO, A. M., "Aproximación a una teoría de los "actos constitucionales»", Revista de Derecho Político, núm. 46, 1999, pp. 44-49, y, del mismo autor, "Los actos parlamentarios con fuerza de ley", Corts. Anuario de Derecho Parlamentario, núm. 7, 1999, pp. 280-287.
} 
contencioso-administrativos contra los decretos de declaración y de prórroga, pero sin éxito, porque ambos recursos fueron rechazados por el Tribunal Constitucional. Y el problema ha vuelto a suscitarse en la primavera de 2020 con ocasión del estado de alarma declarado para la gestión de la crisis sanitaria provocada por la COVID-19, cuyos decretos de declaración de prórroga fueron nuevamente recurridos ante la jurisdicción contenciosoadministrativa, esta vez por el cauce procedimental de la protección jurisdiccional de los derechos de la persona, de nuevo sin éxito, y mediante un recurso de inconstitucionalidad presentado por los diputados del Grupo Parlamentario Vox, cuya resolución, todavía pendiente, permitirá al Tribunal Constitucional zanjar, con alcance general y eficacia erga omnes, las dudas y reticencias que alguna doctrina y el propio Tribunal Supremo, a tenor del contenido de sus AATS 2478/2020 y 2508/2020, mantienen sobre la naturaleza de los decretos de declaración y de prórroga del estado de alarma y la jurisdicción competente para revisarlos.

Junto a esa cuestión, el máximo garante de la Constitución analizará la concurrencia de los vicios de inconstitucionalidad alegados por los recurrentes, relativos a la disyuntiva entre limitación y suspensión de derechos que las restricciones de la libertad circulatoria habrían suscitado y a la improcedencia del estado de alarma en lugar de haber declarado el estado de excepción. El Tribunal Constitucional podrá así clarificar la naturaleza gradual o cualitativamente distinta de los estados de alarma y de excepción, precisar los límites de las medidas standard previstas en la LOAES y determinar el alcance interpretativo que cabe conferir a los principios de necesidad y proporcionalidad en la aplicación del derecho de excepción. Y no será la única ocasión en que el Tribunal Constitucional se pronuncie sobre ello, porque el 17 de noviembre de 2020 el Pleno admitió a trámite un nuevo recurso de inconstitucionalidad presentado por cincuenta y un diputados del Grupo Parlamentario Vox contra la declaración del estado de alarma decretado el 25 de octubre de 2020 y su decreto de prórroga, lo que le permitirá precisar la procedencia de la delegación de autoridad en otras autoridades distintas al Gobierno y si la prórroga está sometida a término o el Congreso de los Diputados es libre para fijar su duración. El Tribunal Constitucional tendrá, por tanto, más de una ocasión para subrayar que, pese a sus limitaciones, el derecho constitucional 
fundación

Manuel Giménez Abad

deEstudios Parlamentarios ydelEstado Autonómico

de excepción es también derecho y que, donde está instituido y garantizado, la excepción no crea su propia ley ni doblega la normatividad de la existente. 